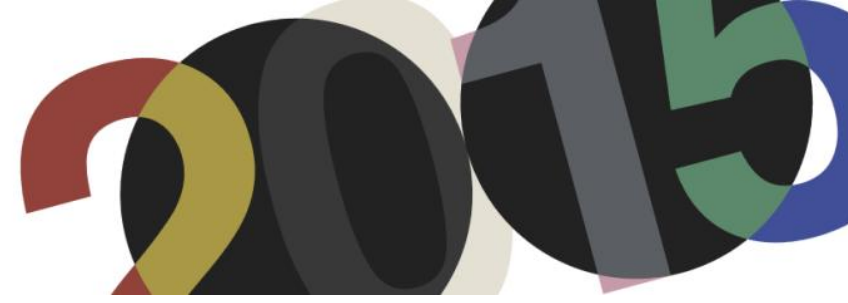

DOI: http://dx.doi.org/10.4995/LC2015.2015.680

\title{
Dibujando La Casa Peyrissac
}

\author{
A. Saseta Naranjo \\ Doctoranda en el Departamento de Proyectos Arquitectónicos de la ETSA de Barcelona (UPC, España) y \\ Lecturer en Dar Al Uloom University (Riad, Arabia Saudí)
}

\begin{abstract}
Resumen: Se trata de imaginamos en la piel de un empleado de Le Corbusier al que se le encomienda la misión de pasar a limpio unos croquis relativos al proyecto de una casa. Los croquis mencionados son realizados por Le Corbusier en 1942, durante su estancia en Argel, y hacen referencia a una casa diseñada para una propiedad agrícola cerca de la Montaña Chenoua perteneciente a la familia Peyrissac. Disponemos de dichos croquis gracias a la Fundación Le Corbusier y también contamos con la información ofrecida por La Euvre Complète, aunque en su mayoría consiste en una selección de los mismos dibujos acompañados de algunas notas aclaratorias. Por razones de operatividad se ha optado por recurrir a la tecnología actual, de esta manera todos los dibujos han sido realizados por ordenador. Básicamente nos hemos centrado en una serie de dibujos, que consideramos son los últimos cronológicamente hablando y que representan la planta baja, primera y de cubiertas, una sección transversal de la casa, y sendas axonometrías. También hemos prestado atención al resto de la documentación existente, especialmente a los dibujos que hacen referencia a la implantación de la casa en su entorno, a la organización global y al programa de necesidades, así como cualquier información concreta sobre dimensiones. Hemos insertado la casa en la parcela original, previa búsqueda de la misma, hemos dibujado la planta baja, la planta primera, y una sección transversal, todo ello atendiendo a la información prestada por los dibujos originales del maestro. Como ejercicio hemos dibujado una hipótesis de detalle constructivo de cubiertas.
\end{abstract}

Abstract: It is imagined to be a Le Corbusier employee who is commissioned to draft a house based on some original drawings. These drawings are made by Le Corbusier in 1942, during his stay in Algeria, and refer to a house designed for an agricultural property near the Mountain Chenoua which belongs to Peyrissac family. The original drawings have been provided by Le Corbusier Foundation. Also, The Euvre Complète provides information for this project, although mostly consists of a selection of the same drawings accompanied by some explanatory notes. For operational reasons it is decided to use current technology, so all drawings have been made by computer. Basically it has been focused on a series of drawings, which it is believed are the last ones and represent the ground, first floor plan and the roof, also a cross-section of the house, and two axonometrics. It has been paid attention to other existing documentation, especially drawings that refer to the implementation of the house in its surrounding, the organization and the program requirements, as well as any specific information about dimensions. The house has been inserted in the original plot and the ground floor, first floor, and a cross section have been drawn, based on the information provided by the original drawings of the Master. As an exercise, a hypothetical construction detail of the roof has been drawn.

Palabras Clave: Le Corbusier; Peyrissac; Chenoua; Argel; Croquis; Casa.

Keywords: Le Corbusier; Peyrissac; Chenoua; Argel; Sketch; House.

\section{Introducción}

El cuerpo de este trabajo se realiza como ejercicio de curso, en el seminario titulado Análisis de Obras y Proyectos, impartido por Josep Quetglas en los Cursos de Doctorado del Departamento de proyectos Arquitectónicos, en el año 2005. Para este congreso, el trabajo ha sido revisado y ampliado significativamente.

El ejercicio consiste en imaginarnos en la piel de un empleado de Le Corbusier al que se le encomienda la misión de pasar a limpio unos croquis relativos al proyecto de una casa. Sin muchas explicaciones, se le 
proporciona una carpeta llena de bocetos a mano alzada y se le pide que delinee la casa completa. Tendremos que averiguar la cronología de los croquis, analizar cada dibujo y cada anotación, y resolver las posibles contradicciones típicas del método prueba-error de las primeras fases de un proceso de diseño. Como somos un empleado veterano, instruido en el modus operandi del maestro, nos podremos apoyar en soluciones adoptadas en otros proyectos.

Los croquis mencionados son realizados por Le Corbusier en 1942, durante su estancia en Argel, y hacen referencia a una casa diseñada para una propiedad agrícola cerca de la Montaña Chenoua, perteneciente a la familia Peyrissac.

Por razones de operatividad se ha optado por recurrir a la tecnología actual, de esta manera todos los dibujos han sido realizados por ordenador.

Siendo el objetivo del trabajo "pasar a limpio" la información existente en los croquis originales, después de un análisis y clasificación de los mismos, nos hemos centrado en una serie de dibujos, que consideramos son los últimos cronológicamente hablando, y que representan la planta baja, primera y de cubiertas, una sección transversal de la casa, y sendas axonometrías. También hemos prestado atención al resto de la documentación existente, especialmente a los dibujos que hacen referencia a la implantación de la casa en su entorno, a la organización global y al programa de necesidades, así como a cualquier información concreta sobre dimensiones.

\section{Dibujando La Casa Peyrissac}

\subsection{Clasificación y análisis de los croquis originales}

Lo primero que hemos hecho ha sido analizar la información original existente relativa a La Casa Peyrissac, la cual consiste en 36 croquis originales a los que hemos tenido acceso en su totalidad gracias a La Fundación Le Corbusier $^{l}$, y a 8 Páginas de La Euvre Complette ${ }^{2}$ dedicadas a dicha casa, que consisten, básicamente, en la reproducción de algunos de los croquis previamente mencionados a los que se le han añadido anotaciones, en algunos casos muy esclarecedoras.

Después de analizar los 36 croquis previamente mencionados, hemos asociado a cada uno de ellos diferentes temáticas y los hemos relacionado en una tabla. Las temáticas mencionadas son: La implantación en la parcela, la relación de la casa con las principales vistas, con el límite de la propiedad, con el camino comunal y con la disposición de la piscina; las cotas de nivel, el programa de necesidades, las plantas, las secciones, las fachadas, la estructura, la cubierta, la volumetría definitiva y todo lo relativo a dimensiones generales y materiales. Por último, hemos señalado cada detalle que nos puede ayudar a encontrar la parcela dentro de la planimetría de Argel.

A continuación se adjunta una tabla con el listado de imágenes y su clasificación según temáticas, así como 4 tablas más con los croquis originales agrupados. Por cuestiones de espacio se han omitido 4 croquis que no se han considerado relevantes para este trabajo.

\footnotetext{
${ }^{1}$ Colección de 36 croquis originales dibujados por Le Corbusier en relación a La Casa Peyrissac y facilitadas por La Fundación Le Corbusier. Ver listado, clasificación y análisis de los mismos en las tablas 1, 2, 3, 4 y 5.

${ }^{2}$ Le Corbusier Euvre Complète Volume 4. 1938-46. 14 ed. Birkahauser, Basel: W. Boesiger, 2013.
} 

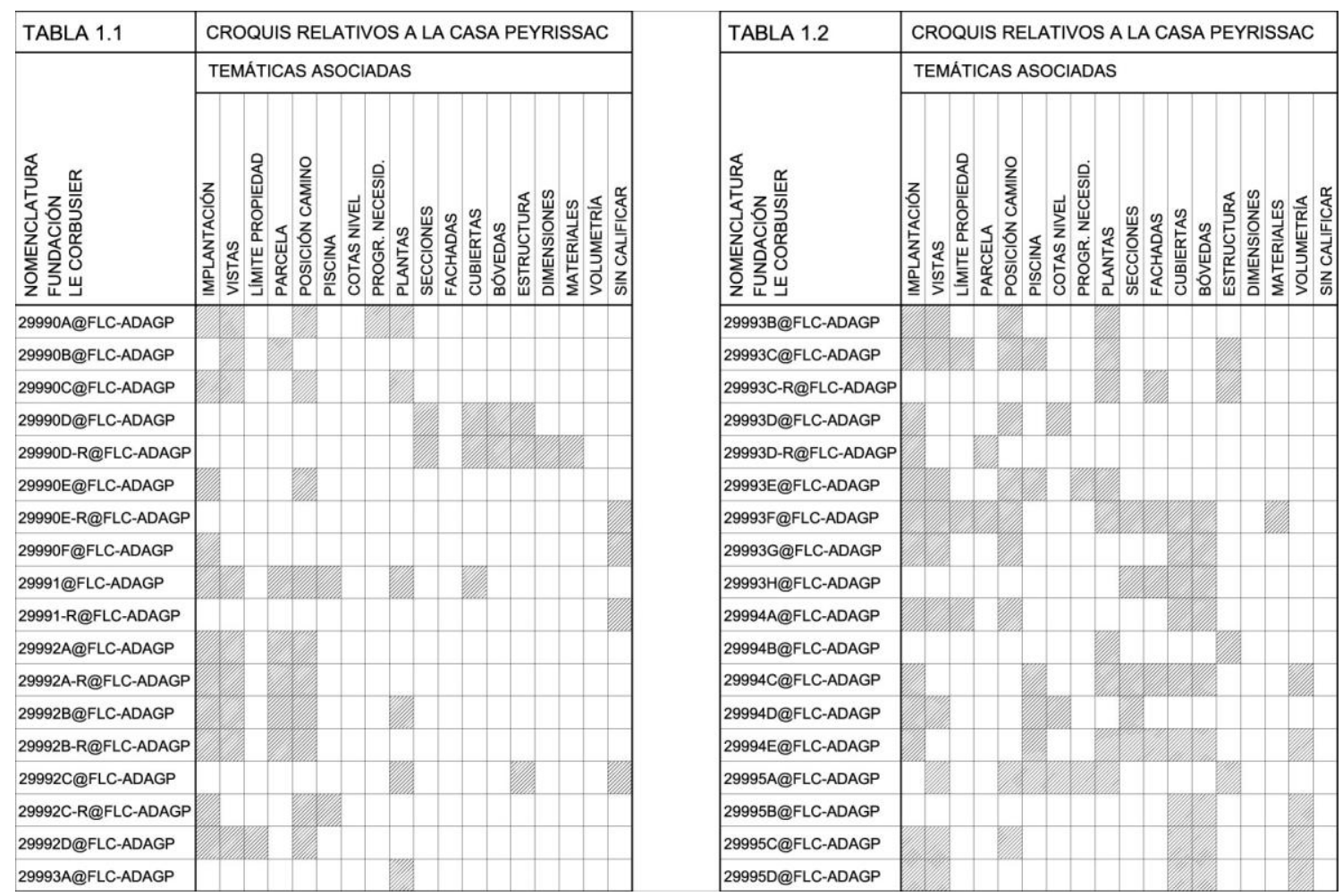

Tabla 1. Clasificación y análisis de los croquis originales.

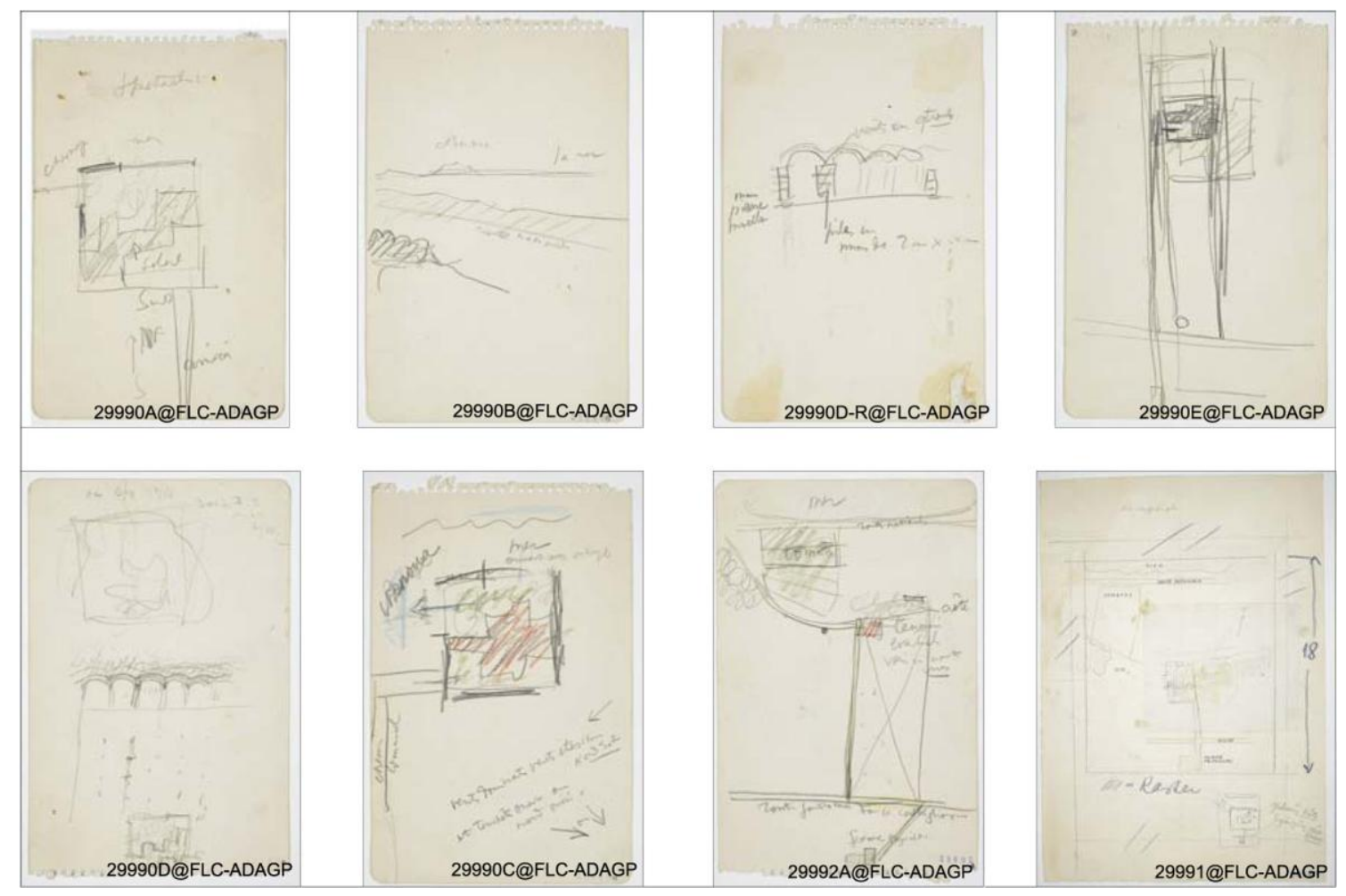

Tabla 2. Relación de croquis originales. 


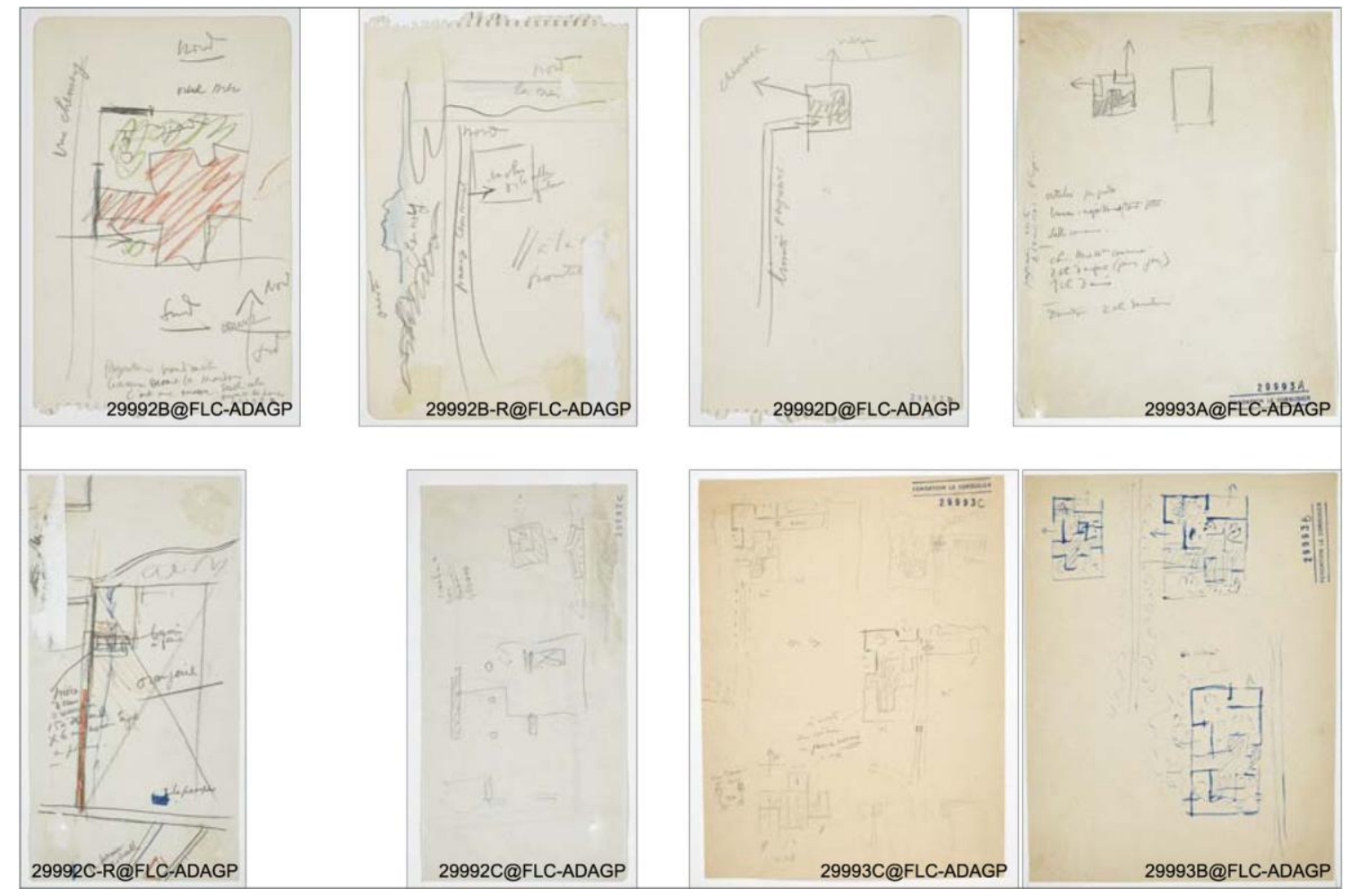

Tabla 3. Relación de croquis originales

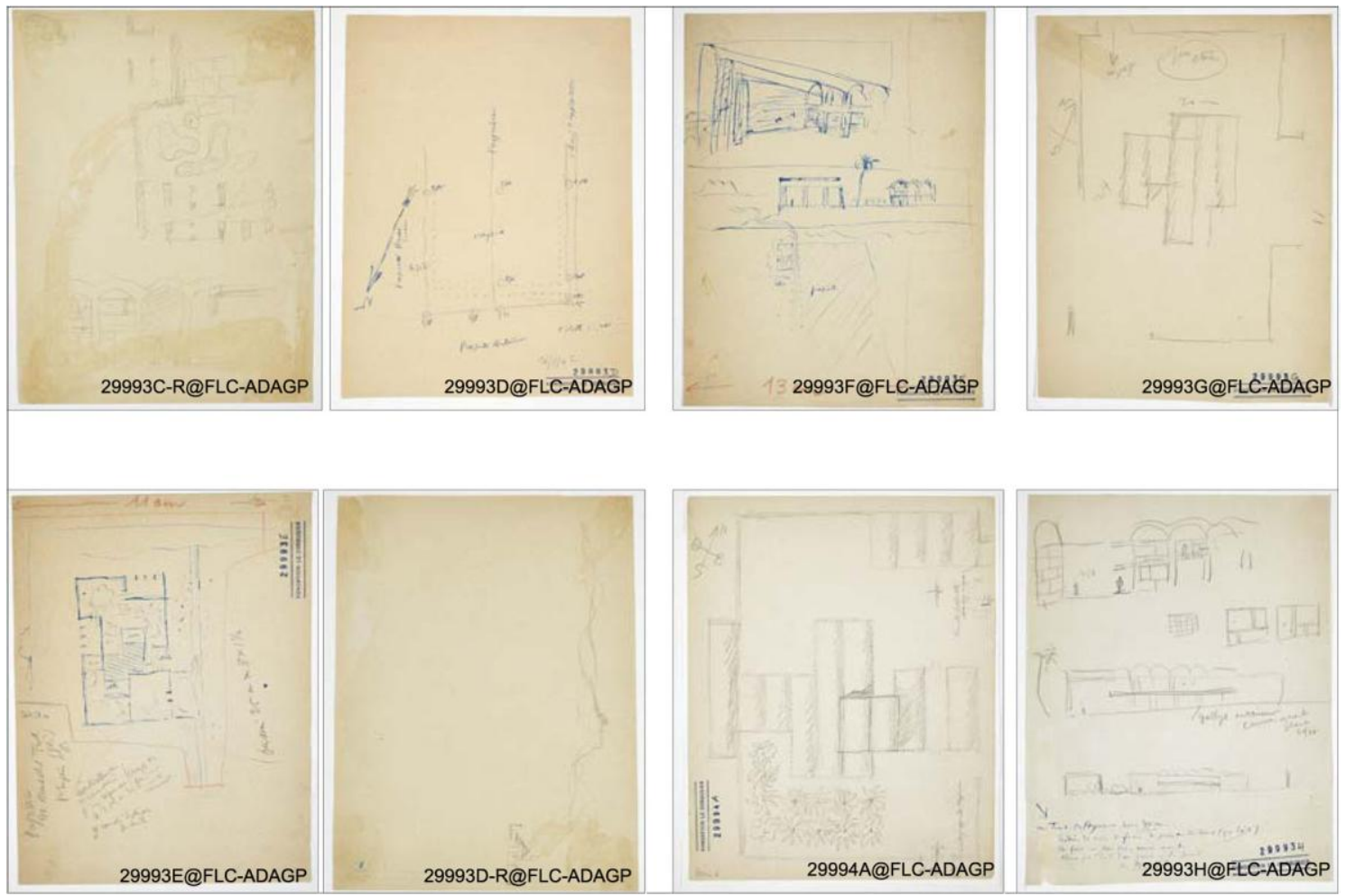

Tabla 4. Relación de croquis originales. 


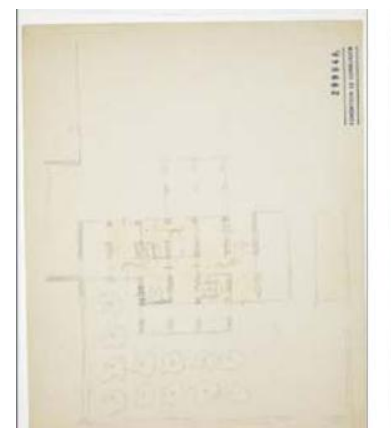

29994B@FLC-ADAGP
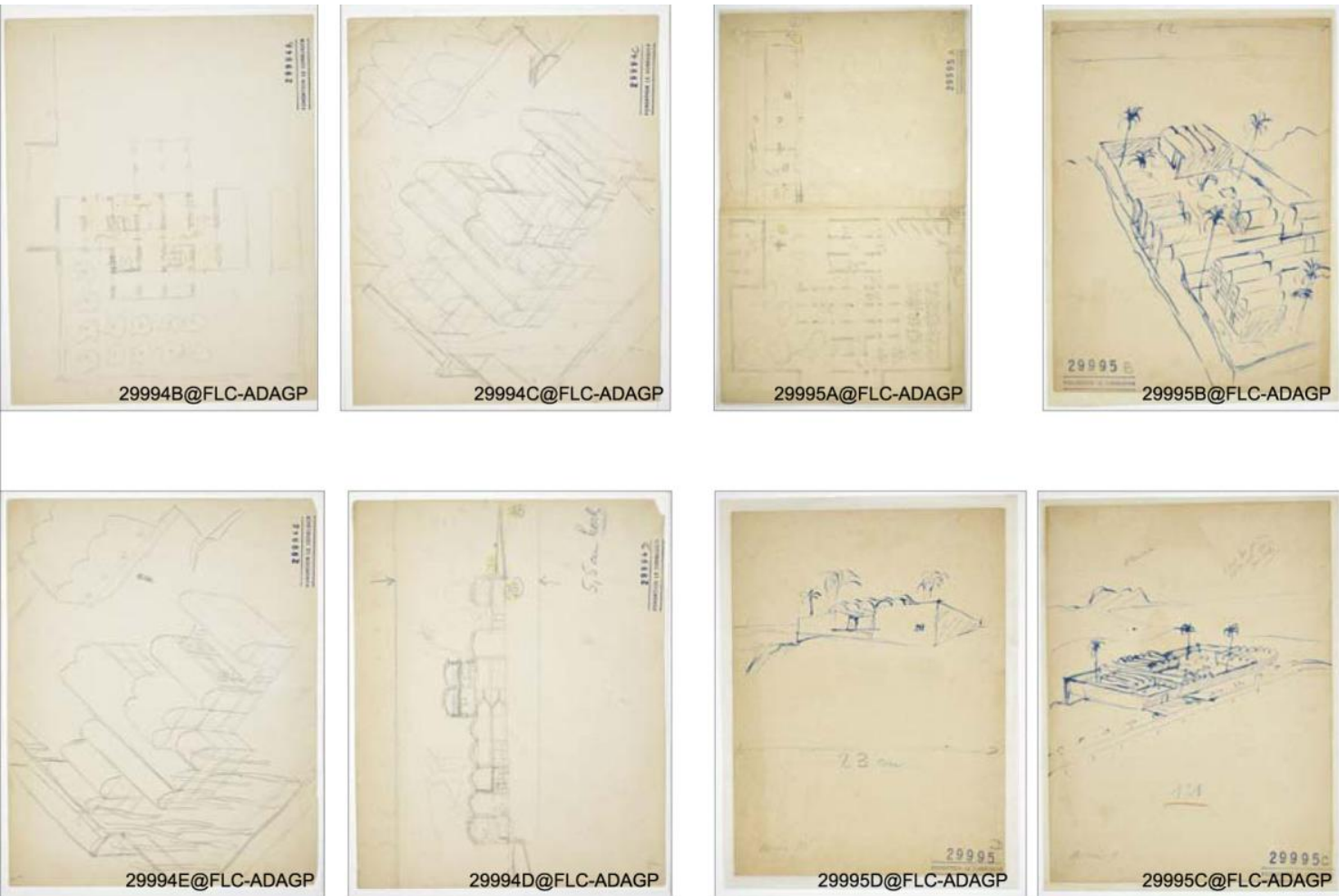

Tabla 5. Relación de croquis originales.

\subsection{La configuración general de la casa}

Desde los primeros croquis, Le Corbusier dibuja la Casa Peyrissac contenida en un perímetro rectangular con sólo parte de su superficie interior construida, y dos grandes aberturas al norte y al oeste (gabinetes de vistas). En las primeras versiones dicho rectángulo es en realidad un cuadrado y las aberturas ocupan aproximadamente la mitad del lado del cuadrado, estando situadas una en el este del lado norte del cuadrado y la otra en el norte del lado oeste del mismo, apuntando cada una de ellas, como bien se anota en los dibujos, a las mejores vistas, la abertura del norte mirando al mar y la del oeste a la Montaña Chenoua. En todos estos primeros dibujos, dentro del recinto cuadrado, aparece un polígono irregular que se representa tramado, e identificamos con el área techada de la casa, cuya silueta es en cada dibujo diferente pero en todos ocupa aproximadamente un $40 \%$ de la superficie del cuadrado, y se desarrolla de oeste a este, llegando a tocar los correspondientes perímetros en dichos puntos cardinales. Esta primera configuración la encontramos en los croquis 29990A@FLC-ADAGP, 29990C@FLC-ADAGP, 29990E@FLC-ADAGP,29992B@FLC-ADAGP, 29992D@FLC-ADAGP y por último el 29993A@FLC-ADAGP, donde aparece un cuadrado con las características anteriores, con la diferencia de que los gabinetes de vistas se representan como sendos rectángulos acoplados al muro perimetral. En este dibujo también se detalla el programa de necesidades y aparece un rectángulo vacío cuyas proporciones son el cuadrado anterior más la mitad del mismo, constituyendo el primer pensamiento del maestro en cuanto a un cambio de proporción en la forma prevista.

En el croquis 29993B@FLC-ADAGP aparecen tres dibujos muy similares de la planta. El recinto es un rectángulo de proporciones diferentes en cada uno de ellos. La parte construida se representa tramada a rayas y se desarrolla de oeste a este tocando dichos perímetros. El perímetro sur aparece exento, sin ninguna construcción adosada al mismo. Los gabinetes de vistas se representan como sendos rectángulos añadidos al perímetro, ambos con una abertura lateral desde lo que se supone es el patio interior. Por primera vez, hay una intención constructiva en el grosor con el que se dibuja el perímetro de la casa, representado como un muro que, 
cuando llega a la abertura destinada a los gabinetes de vistas, se retranquea hacia el interior, dejando un rectángulo que representa un volumen sin cerrar, quedando expuesto a las inclemencias del entorno y a las virtudes de las vistas. Observando el croquis 29995D@FLC-ADAGP entendemos mejor las intenciones plásticas del maestro.

Al cambiar las proporciones del cuadrado al rectángulo, el gabinete de vistas oeste cambia de posición, encontrándose ahora, aproximadamente, en el centro del lado oeste de dicho rectángulo, adosado a la parte techada de la casa.

Los croquis siguientes confirman los presupuestos formales y de proporciones realizados hasta ahora, preocupándose el maestro a partir de ahora por otras cuestiones como: Los elementos estructurales de la casa, la configuración del programa de necesidades, las dimensiones generales y la posición de la casa respecto al camino comunal que llega a la parcela.

\subsection{Los elementos estructurales}

En La Euvre Complète, página 122, se menciona que la estructura está constituida por pilastras cuadradas, muros y medios muros.

En la esquina inferior izquierda del croquis 29993C@FLC-ADAGP, encontramos un esquema en el que se propone una distancia entre ejes de 4 metros y muros de 50 centímetros de espesor, quedando una distancia libre de 3,5 metros. Esta información se confirma en el mismo croquis, ya que a la derecha del dibujo anterior hay otro esquema en el que aparecen 7 crujías acotadas en un total de 28 metros. Aunque arriba en el mismo croquis encontramos información contradictoria, acotándose el ancho de la casa en 25 metros, entendemos que este último esquema es una aproximación realizada antes de haber hecho la reflexión sobre cuál podría ser la distancia óptima entre ejes. En el croquis 29992C@FLC-ADAGP observamos un dibujo que aparenta ser una trama de elementos estructurales, variando desde elementos cuadrados a rectangulares de dos tamaños, pudiéndose interpretar dichos elementos como pilastras, muros y medios muros. El croquis 29993C@FLCADAGP representa una vista parcial de la planta de la casa, donde aparece la esquina sur-oeste y el gabinete de vistas oeste, y donde claramente confirmamos la existencia de tres tipos de elementos estructurales.

Los siguientes dos croquis a analizar serían el 29995A@FLC-ADAGP y el 29994B@FLC-ADAGP. Como se menciona en La Euvre Complète, páginas 120 y 121, dichos dibujos corresponden a la planta baja y primera respectivamente. En ambos croquis aparecen todos los elementos estructurales, confirmándose la existencia de las pilastras, los muros y los medios muros.

Después de este análisis previo, empezamos a dibujar. El primer paso que se ha dado consiste en pasar a limpio la información existente para la planta baja. Insertamos el croquis 29995A@FLC-ADAGP en el programa de dibujo y proporcionamos dicho croquis, teniendo en cuenta una trama de ejes separados 4 metros en el sentido transversal, de oeste a este. En el croquis que estamos usando de referencia en nuestro dibujo aparecen 10 crujías longitudinales, si el ancho de las mismas es de 4 metros, el ancho total de la casa resulta 40 metros. Este hecho resulta contradictorio con los 28 metros anteriores que nos indicaba la anotación del croquis 29993C@FLCADAGP, sin embargo, lo damos por válido apoyándonos para ello en el siguiente razonamiento: Si observamos el croquis 29993G@FLC-ADAGP vemos que se propone una primera etapa en la construcción del proyecto, consistente en cinco crujías, acotadas un ancho total de 20 metros, lo cual confirma la tesis de que el ancho de cada crujía se debe mantener en 4 metros. 
Teniendo fijado el ancho, el siguiente paso es acotar la longitud de las crujías. Observando el croquis 29995A@FLC-ADAGP se intuye claramente que podríamos superponer una trama perpendicular a la anterior, cuya separación entre ejes fuera también de 4 metros. Esta segunda trama nos ayudaría a situar los principales elementos de la casa. De esta manera, obtenemos una malla ortogonal de 4 x 4 metros. El primer indicio del éxito de esta operación es comprobar que los centros de gravedad de las pilastras cuadradas coinciden con puntos de intersección de la trama, así como que la posición de los muros perimetrales de la casa y de las líneas generales que definen la plataforma, donde se sitúa la piscina, entran dentro de la lógica geométrica que la trama propone.

El siguiente paso consiste en fijar la posición y dimensiones tanto de los elementos estructurales como de los muros perimetrales. Para la definición de los elementos estructurales nos apoyamos en los siguientes argumentos: el ancho lo consideramos fijado en 50 centímetros ( 25 centímetros a cada lado del eje), y el largo lo definimos basándonos en que los elementos estructurales consisten en pilastras cuadradas, muros y medios muros, y atendiendo a la información brindada por el croquis 29990D-R@FLC-ADAGP, en el cual se dibuja un esquema en sección donde aparecen unos muros de ladrillo que sustentan bóvedas. De uno de los muros sale una flecha con una anotación que dice: "Pilastras y muros de 2 metros x 50 centímetros"”. En el croquis 29995A@FLC-ADAGP, efectivamente, se han dibujado tres tipos de soportes estructurales, siendo perfectamente coherente suponer que las pilastras cuadradas son de 50 x 50 centímetros, situadas, como hemos mencionado anteriormente, con su centro de gravedad coincidiendo con las intersecciones de la trama ortogonal. Los medios muros los fijamos en 2 metros de largo, y los situamos teniendo en cuenta que sus dos esquinas más cercanas a los puntos de intersección de la trama deben distar de dichos puntos 25 centímetros tanto en la dirección X como en la Y. Por último, los muros enteros los consideramos del largo total del módulo que propone la trama, es decir 4,5 metros, ya que entendemos que para seguir una retícula lógica han de distar cada una de sus esquinas 25 centímetros, en los ejes $\mathrm{X}$ e Y, de los puntos de intersección de la trama.

El muro perimetral lo hemos dibujado en concordancia con las proporciones que el croquis 29995A@FLCADAGP nos sugiere, utilizando de guía los ejes correspondientes propuestos en la trama ortogonal. De esta manera obtenemos que la casa está contenida en un recinto rectangular de 36,50 metros de ancho por 52,50 metros de largo.

El gabinete de vistas norte permanece en su posición inicial, constituyéndose como un recinto rectangular con apertura a la plataforma de la piscina y separado del conjunto de la casa. Sin embargo el gabinete de vistas oeste mantiene su posición en el eje $\mathrm{Y}$, pero avanza hacia el exterior del perímetro de la casa en el eje $\mathrm{X}$, quedando adosado al rectángulo que conforma el perímetro de la casa como un saliente de 4 metros de ancho por 12,50 metros de largo, situado a 16 metros en el sentido longitudinal de la esquina sur oeste de dicho rectángulo.

\subsection{La piscina}

En el croquis 29995A@FLC-ADAGP la piscina aparece situada en una plataforma que tiene continuidad con el gabinete de vistas norte. Esta plataforma está acotada como un rectángulo de las siguientes dimensiones: en el sentido transversal, de oeste a este, 8 metros, más 25 metros, más una longitud que no está definida, y que, según las proporciones generales, debería ser precisamente 4 metros. En el sentido longitudinal se vuelven a acotar tres medidas, de norte a sur, 8 metros más 8 metros, que corresponde a la piscina, más 1 metro. Al comprobar las medidas, dentro de la lógica del dibujo, encontramos que los primeros 8 metros están desproporcionados y que

\footnotetext{
${ }^{3}$ Todas las anotaciones que acompañan los dibujos originales, y que se han usado en la presente comunicación, han sido traducidas del francés por la autora.
} 
más bien corresponderían a 4 metros. De esta manera la piscina adquiere unas dimensiones de 25 metros por 8 metros y se inserta a su vez en un rectángulo de 36 metros por 13 metros. Este rectángulo se adosa al gabinete de vistas situado al norte mediante una segunda plataforma, en continuidad física con la anterior, que se acota en el dibujo en 4 metros transversales, de oeste a este, por 8 metros longitudinales, de norte a sur, y de la cual observamos que las medidas coherentes son exactamente las inversas: 8 metros transversales por 4 metros longitudinales.

Siguiendo la cronología de los croquis existentes en la fundación Le Corbusier, la primera vez que aparece la piscina es en el croquis 29991@FLC-ADAGP, donde podemos apreciar la posición de la casa en relación a los principales elementos de su entorno, la piscina se encuentra situada en el extremo superior este de la casa adosada a ella como un apósito. Sin embargo, más tarde demostraremos que este dibujo es posterior y que el maestro reflexionó sobre la piscina antes de llegar a la configuración que en este dibujo propone. Nos paramos en el dibujo 29992C-R@FLC-ADAGP, según nuestro juicio, anterior al mencionado y donde por primera vez aparece una anotación referente a la piscina que dice: "Tamaño del pozo 15 a 20 x $6 \mathrm{~m}$ debajo del suelo". La siguiente referencia aparece en el croquis 29993C@FLC-ADAGP, y es la primera vez que la piscina aparece dibujada en posición y dimensiones similares a las que encontramos en el croquis de referencia 29995A@FLCADAGP. En este dibujo, la piscina está separada de la casa por el camino comunal, tema que discutiremos más tarde, y se acota en 25 metros para la piscina y 3 metros para un elemento que tiene continuidad geométrica con la misma y se encuentra situado al este. Este mismo elemento lo habíamos acotado anteriormente en 4 metros, siguiendo la lógica geométrica del dibujo, pero al encontrar un dato preciso, decidimos dibujar su ancho en 3 metros.

La siguiente referencia es el croquis 29993E@FLC-ADAGP donde encontramos una anotación que dice: "Piscina $25 \times 8 \times 1$ 1/2". Medidas que son perfectamente coherentes con nuestro dibujo. Respecto a la anotación encontrada en el croquis 29992C-R@FLC-ADAGP, donde se hace referencia a un pozo, podemos olvidarnos gracias a una anotación encontrada en La Euvre Complète, página 120, que dice: "La piscina sirve de sistema de riego para la plantación"

\subsection{El camino comunal y la necesidad de comprar la parcela colindante}

El camino comunal que llega a la parcela es un elemento de estudio recurrente desde los primeros croquis. Llama la atención el hecho de que la posición de la casa varía respecto al camino varias veces a lo largo del proceso. En los primeros croquis el maestro se muestra dubitativo, dibujando el camino al este o al oeste de la casa, en algunos casos muriendo en la esquina sur-este del recinto, y en otros dejando que transcurra paralelo a la casa al oeste de la misma, pegado o separado de ella. Observamos este hecho en los croquis clasificados como 29990E@FLC-ADAGP y 29992A-R@FLC-ADAGP donde, a modo de garabato, podemos ver el recinto de la casa con las dos opciones de caminos posibles.

Entendemos la duda del maestro cuando llegamos al croquis 29993C@FLC-ADAGP, donde hay varios dibujos de la planta de la casa; en un primer dibujo observamos el recinto rectangular de la casa, con la piscina adosada a la esquina superior del lado este y el camino muriendo en la esquina sur-oeste. A la derecha, encontramos un segundo dibujo donde se representa otra vez el recinto de la casa, pero esta vez con el camino situado entre la casa y la piscina y acompañado de una anotación que dice: “A comprar para asegurar vistas". En el croquis anterior 29992D@FLC-ADAGP encontramos una anotación al este del camino que dice: "Límite Peyrissac”.

\footnotetext{
${ }^{4}$ Todas las citas tomadas de La Euvre Complète y que se han usado en esta comunicación han sido traducidas por la autora.
} 
Por último observando el croquis 29993F@FLC-ADAGP encontramos un esquema de la situación de la casa en su entorno donde se representan tres elementos: la propiedad, el camino y la villa, estando la villa fuera de la propiedad. Por todo ello concluimos que Le Corbusier propuso a su cliente comprar la parcela colindante al oeste porque, por razones que veremos más adelante, esta parcela tenía mejores vistas que la del propio Peyrissac.

Una vez tomada la decisión de comprar la parcela colindante, el camino siempre aparece al este de la casa, transcurriendo paralelo a la misma, sin embargo, esta configuración dejaba la piscina separada de la casa, razón por la cual entendemos que el maestro decidió finalmente hacer morir el camino en la esquina este del lado sur del recinto de la casa, y poner la entrada a la misma en ese punto. En el croquis 29994A@FLC-ADAGP el camino queda perfectamente acotado en 5 metros de ancho situado a 1 metro al oeste del límite de la propiedad Peyrissac. Esta información se confirma en el croquis 29995A@FLC-ADAGP, el cual es la referencia última de nuestro dibujo.

Es imposible analizar si efectivamente la parcela colindante al oeste tiene mejores vistas sin ubicar primero la propiedad Peyrissac en la planimetría de Argel. A continuación vamos a estudiar la información que tenemos para tratar de localizar la propiedad.

En La Euvre Complète, página 116, se describe perfectamente las virtudes del lugar: "La vista del horizonte está abierto sólo a dos puntos: al norte, el océano; al oeste la Bahía de Cherchell y la magnífica Montaña Chenua; los dos gabinetes de vistas quedarán expuestos al sol y el viento. Una gran plantación de naranjas y tomates en una meseta, limitada por un acantilado que muere en la orilla del mar. La residencia se instalará en la parte superior del acantilado para disfrutar de las dos vistas mencionadas".

El croquis 29991@FLC-ADAGP representa la casa en relación a todos los elementos de su entorno. Por su clasificación este croquis debería ser uno de los primeros de la serie, sin embargo advertimos que es posterior ya que en él se observan decisiones que se han tomado casi al final del proceso: El camino está situado en la esquina sur-este del recinto de la casa; la piscina está situada, como un apósito, en el norte del lado oeste; las dimensiones generales de la casa y la piscina, así como la posición de los gabinetes de vistas, son similares a lo propuesto en el croquis 29995A@FLC-ADAGP; incluso podemos advertir las diferentes crujías con sus ejes. Por otro lado, este es el dibujo que Le Corbusier eligió para explicar la situación de la casa en La Euvre Complète. Por todo lo dicho, concluimos que es un dibujo considerado definitivo donde deberían estar todos los elementos del contexto que afectan al diseño de la casa, y, además, nos pueden dar información relevante para encontrar la parcela en la planimetría de Argel.

Analizando el croquis anterior sabemos que nuestra parcela está situada en una zona agrícola, orientada norte-sur pero con una ligera inclinación hacia el oeste, que al norte se encuentra el mar y al oeste la Montaña Chenoua, que la carretera nacional queda al norte, que entre la parcela y la carretera nacional no hay conexión, que a la parcela llega un camino comunal que viene del sur y conecta con una carretera regional, que a su vez nos lleva a otra finca perteneciente a la familia Peyrissac. A pesar de que el lado norte del perímetro de la casa está adosado a una línea con cierta curvatura que continúa tanto al este como al oeste, el hecho de que esta línea represente el borde de un acantilado no queda claro hasta que en La Euvre Complète, página 118, leemos una anotación que dice: "La composición termina en el borde del acantilado". Volvemos a los croquis y vemos que la línea que representa el borde del acantilado es un elemento recurrente en todos los dibujos que presentan la casa en su entorno y nos paramos en el croquis 29993D-R@FLC-ADAGP, donde se dibuja un perfil del terreno a gran escala en el que vemos el recinto de la casa en el borde del acantilado.

Con todos estos datos nos vamos a la planimetría de Argel y buscamos una parcela en una zona agrícola al este de la Montaña Chenoua, orientada norte-sur con una ligera inclinación al oeste, limitada por un acantilado en su 
linde norte y por un camino comunal en su linde oeste ${ }^{5}$. La característica determinante es que la parcela que colinde con ella al oeste tenga el suficiente atractivo para que Le Corbusier insistiera en que era necesario comprar un trozo para situar allí la casa.

Tras explorar la zona, concluimos que la parcela debe estar situada entre Le Chenoua y el pueblo de Fouka, donde hay una zona agraria con bastantes parcelas de características compatibles con la que estamos buscando. Para localizar la nuestra nos hemos apoyado en una anotación encontrada en La Cuvre Complète, página 119, aparece una planta de la casa, anterior a la que estamos usando de referencia para nuestro dibujo, y arriba de la misma se escribe: "el mar" y abajo: "Le Chenoua, La Tumba de la Cristiana". La tumba de la Cristiana es el nombre que en francés, traducido en este caso, se le otorga al Mausoleo Real de Mauritania, el cual es un monumento funerario que se encuentra entre Le Chenoua y Fouka, exactamente en el área donde estamos buscando nuestra parcela.

Efectivamente, al norte del Mausoleo, al otro lado de la carretera, encontramos una parcela con características compatibles a la nuestra en términos de orientación, situación al borde del acantilado y flanqueada por un camino comunal al oeste, en la cual nos fijamos precisamente por la morfología de la parcela que linda con ella al oeste. Dicha parcela tiene un entrante del acantilado que, a su vez, la separa de la parcela más al oeste haciendo que su extremo termine en un pequeño promontorio, que, al situar la casa en el mismo, garantizaría las vistas de la Montaña Chenoua al este. Más adelante, cuando dibujemos el plano de situación, comprobaremos si la casa encaja o no en este promontorio.

\subsection{Las cotas altimétricas}

El siguiente paso es estudiar los diferentes niveles de la planta baja y para ello lo primero que hacemos es analizar las cotas altimétricas originales del terreno. La planimetría de la zona de la cual disponemos está representada a escala 1:50000, limitándose la información sobre cotas altimétricas a unas curvas de nivel que a esa escala poco pueden ayudarnos. Consideramos mejor estrategia centrarnos en la información recogida por el propio Le Corbusier.

Existe un croquis clasificado como 29993D@FLC-ADAGP en el que se realiza un intento de detallar la topografía del terreno. Tan sólo está dibujada la finca propiedad de Peyrissac, ya que el dibujo orientado al norte, se acaba en el camino comunal, situado al oeste. Entendemos que la superficie a la cual hace referencia el dibujo, es la franja de tierra, en el norte de la parcela, donde estaba previsto ubicar la casa. Vemos que el camino empieza teniendo una cota de +1.80 metros, sube a +2.48 metros para volver a bajar en el extremo a +1.82 metros. Los mismos puntos desplazados a la derecha del camino son +2.70 metros, +3.70 metros y +3.21 metros. Existen otros tres puntos similares más al este que decidimos obviar ya que suponemos que una vez establecida la decisión de situar la casa en la propiedad colindante carecen de interés.

Volvemos al croquis 29995A@FLC-ADAGP que estamos usando como referencia para nuestro dibujo y representa la planta baja. La información es confusa, pero podemos sacar cosas en claro. Aparece una primera cota de +1.80 metros en la entrada de la casa, precisamente donde muere el camino. Dentro del gabinete de vistas norte y en el extremo este de la plataforma de la piscina aparece una segunda cota, que se repite en ambos casos, y es +3.70 metros. Estas dos cotas son significativas, ya que resultan coherentes con la información

\footnotetext{
${ }^{5}$ Para buscar la parcela se ha utilizado Google Earth y también un plano topográfico de Argel fechado en Octubre de 1942, perteneciente al U.S. Army Map Service. Washington D.C. y localizado en el sitio web de la Universidad de Texas dentro de la Perry-Catañeda Library Map Collection.
} 
obtenida en el croquis 29993D@FLC-ADAGP. Encontramos dos cotas más: +2.48 metros al sur del gabinete de vistas norte $\mathrm{y}+3.70$ metros al oeste de la plataforma de la piscina, fuera de la misma.

La cota que se encuentra al sur del gabinete de vistas norte y que es +2.48 metros la identificamos como la segunda cota del camino vista en el croquis 29993D@FLC-ADAGP. Si la parte sur de la casa se encuentra a +1.82 metros y la norte a +2.48 metros, supondría que la casa debería tener una pendiente aproximada del $1.5 \%$, lo cual es improbable, ya que su uso se tornaría muy incómodo; por otro lado, tampoco existe ninguna escalera que indique que pueda haber un cambio de cota. Es más lógico suponer que Le Corbusier pensara dejar toda la planta baja en una superficie plana a la cota de entrada, +1.80 metros, a excepción del gabinete de vistas norte y la plataforma que contiene la piscina que estarían ambos a +3.70 metros de altura.

En el croquis 29995A@FLC-ADAGP observamos como del extremo sur-oeste de la plataforma de la piscina sale una pasarela en la dirección este oeste de ancho 1 metro. Según el dibujo en planta, en un momento determinado, la pasarela se convierte en escalera para después volver a ser plana y morir en otra escalera. Entendemos que este elemento supone la unión física entre la casa, la piscina y el gabinete de vistas norte, al cual sólo se puede acceder desde la piscina. La cota +2.48 metros anteriormente mencionada, situada al sur del gabinete de vistas norte, pudiera referirse al segundo tramo de la pasarela anteriormente comentada.

Para comprobar esta información nos vamos al croquis 29994D@FLC-ADAGP, donde se representa una sección transversal de la casa. Por un lado aparecen dos cotas superpuestas +1.80 metros y +2.48 metros en el extremo este de la casa, a la altura del camino, por otro lado aparece +3.70 metros en lo que debería ser la proyección de la plataforma de la piscina, y debajo de esta vuelve a aparecer de nuevo +3.70 metros, esta vez superpuesta con +2.70 metros. Todas las cotas están rodeadas con un círculo amarillo, excepto +1.80 metros y +2.70 metros, rodeadas en azul. Comprobamos en el croquis 29993D@FLC-ADAGP que ambas cotas pertenecen a la parte sur de la antigua parcela y concluimos que la posición de las mismas en la dirección norte-sur debe ser el criterio para rodearlas de distinto color. Como no hay información determinante al respecto, nosotros seguimos con nuestra idea de dejar la planta baja a rasante de la cota +1.80 metros y el gabinete de vistas norte junto con la plataforma que contiene la piscina a +3.70 metros. Respecto a la pasarela, vemos en la sección que no se ha realizado ningún escalón, sino que la unión de ambas cotas se plantea como una rampa, para que esto sea factible necesitamos una longitud de al menos 20 metros. En el dibujo en planta la segunda escalera acaba aproximadamente a la altura del segundo eje en dirección este-oeste, desde ese punto al borde de la piscina son exactamente 20 metros, con lo cual, la elijamos o no, la opción de sustituir las dos escaleras por una rampa es perfectamente coherente con la lógica geométrica del conjunto.

\subsection{Forjados de planta baja y primera}

En planta baja hemos sombreado lo que consideramos el interior de la vivienda, la superficie que suponemos se pretendía pavimentar en madera, tal como se menciona en La Euvre Complète, página 116, entendiendo que el resto se quedaría como suelo de tierra compactada. En principio, hemos considerado que las carpinterías están en los límites de la superficie sombreada, siguiendo los ejes transversales a los elementos estructurales, pero es muy probable que en una fase posterior del proyecto se decidiese retrasar alguna, dejando espacio cubierto a modo de porche.

Para delimitar el forjado de planta primera se ha estudiado el croquis 29995A@ @LC-ADAGP, que representa la planta baja, pero en el cual aparece superpuesta la proyección del forjado de planta primera, reconocible porque la superficie contenida por dicha proyección está tramada. La Euvre Complète, página 120, hay una anotación junto al dibujo al cual nos referimos que dice: "La zona gris indica las áreas con baja altura: 2.20m, quedando 
el resto a 4.50m”. El croquis 29994B @ FLC-ADAGP, donde se detalla la planta primera viene a confirmar la información del croquis 29995A@FLC-ADAGP. Por último el croquis 29994D@FLC-ADAGP que representa la sección nos confirma las suposiciones iniciales. Concluimos que las crujías, que están divididas en más de una planta, son, contando en la dirección oeste-este, la 3,4,5,6,7 y 10, estando esta última dedicada al servicio. Las crujías 4,5 y 6 no están divididas en toda su longitud, quedando espacios a doble altura tanto en la delantera como en la trasera de la casa. El resto del espacio tiene doble altura. En la sección anterior podemos observar también que las crujías 6 y 7 tienen una segunda y tercera altura, que no aparece en ninguna planta pero que por una anotación que aparece en La Euvre Complète, página 12, se destina a cuarto de invitados y aljibe respectivamente. El croquis 29994A@FLC-ADAGP corresponde a una planta global de cubiertas, en el que vemos claramente un volumen cuadrado que sobresale y que corresponde a la prominencia de las crujías 6 y 7 . También confirmamos esta cuestión en los croquis 29994E@FLC-ADAGP y 29994C@FLC-ADAGP que corresponden a sendas axonometrías.

\subsection{Planta de cubiertas y vegetación}

Atendiendo a la lógica constructiva de las bóvedas en sección y al propio dibujo de Le Corbusier procedemos a dibujar la planta de cubiertas, para ello seguimos las directrices establecidas en la planta baja y primera.

Finalmente obtenemos 9 bóvedas longitudinales dirección norte sur que cubren todas las crujías que conforman la casa excepto la crujía 9 que está descubierta. Adicionalmente, separadas del cuerpo principal de la casa, tenemos cuatro bóvedas paralelas a las anteriores que constituyen la cubierta del gabinete de vistas norte.

Relativo a la dirección de las bóvedas hay una contradicción entre los dibujos que queremos aclarar y tiene que ver con los croquis 29993H@FLC-ADAGP y sobre todo con el 29993F@FLC-ADAGP donde se representan sendas secciones generales de la casa y podemos ver como la dirección de las bóvedas en el cuerpo principal de la casa es perpendicular a la que adquieren en el gabinete de vistas norte. Este hecho se confirma en las volumetrías 29995B@FLC-ADAGP y 29995C@FLC-ADAGP, en los cuales las cubiertas del cuerpo principal de la casa y del gabinete de vistas oeste se representan como bóvedas longitudinales en dirección este-oeste y la cubierta del gabinete norte como bóvedas longitudinales perpendiculares a las anteriores. Sin embargo en los dibujos de la última serie constituidos por el 29995A@FLC-ADAGP que representa la planta baja, el 29994B@FLC-ADAGP, que representa la planta primera, el 29994A@FLC-ADAGP, que representa la planta de cubiertas y los croquis 29994C@FLC-ADAGP y 29994E@FLC-ADAGP, que representan sendas axonometrías, la dirección de las bóvedas es norte-sur tanto para la casa como para el gabinete de vistas norte. En último momento el maestro decidió que todas las bóvedas deberían desarrollarse en la misma dirección, quizás por simplicidad estructural o quizás porque los flujos de la casa funcionaban mejor en dirección norte-sur.

En el croquis 29995A@FLC-ADAGP Le Corbusier esboza la vegetación alrededor de la casa. Por un lado, fuera del recinto de la casa al este de la misma y al sur de la piscina, se dibuja una retícula ordenada de árboles, en lo que representa una típica plantación de naranjos y que es acorde con el uso previo de la finca. Dentro del recinto de la casa, en el patio delantero, al sur-oeste de la misma se sitúa una trama de palmeras, muy ordenadas, situadas cada una de ellas en las intersecciones de la continuación de la trama ortogonal usada para la estructura. En el extremo norte de la casa, se plantea otro tipo de vegetación, lo que parecen ser árboles de copa generosa, se sitúan de forma anárquica en el patio trasero. 


\subsection{Plano de situación}

Vamos a proceder a situar la casa en el contexto que estaba prevista y presentarla en un plano de situación. Podemos decir que esta es la "prueba de la verdad", ya que nos confirmará o por el contrario nos dejará en entredicho todas las hipótesis establecidas hasta ahora. Para ello disponemos del croquis $29991 @$ FLC-ADAGP, donde aparece la casa en relación a todos los elementos de su entorno y de la planimetría de Argel, donde, como se ha explicado anteriormente, ya hemos localizado la parcela.

En La Euvre Complète, página 116, encontramos la siguiente afirmación: "Este primer proyecto se elaboró con total precisión y encaja perfectamente en el lugar”. Para insertar la casa en su entorno atendemos a la información que se da en el croquis 29994A@FLC-ADAGP, en el cual se detalla la planta de cubiertas. En la esquina sur este del recinto de la casa, donde muere el camino, se indica que el mismo debe estar en el eje de simetría de la crujía 9, que su ancho es 5 metros y que está situado a una distancia horizontal de 1 metro del límite de la propiedad Peyrissac. En el mismo croquis, al sur del gabinete de vistas norte encontramos una anotación que indica que el límite de la propiedad está a 10 metros de algo que no vemos. Deducimos que ese elemento que no vemos es el límite de la plataforma de la piscina.

Siguiendo las consideraciones anteriores insertamos la casa en la parcela y observamos que encaja perfectamente, tanto es así que su arista norte es idéntica al lado norte de la parcela, y la casa en conjunto queda perfectamente encajada en la protuberancia indicada.

\subsection{Interior de la vivienda y programa de necesidades}

A continuación nos centramos en el interior de la vivienda. En primer lugar situamos la escalera y vemos si es viable en el espacio que se le destina. Ya sabemos por una anotación de La Euvre Complète vista anteriormente que la altura libre de suelo a techo es 2.20 metros que corresponde a "la altura de un hombre con el brazo levantado" y que es la utilizada por Le Corbusier antes del Modulor. Por otro lado en la última página de La Euvre Complète aparece un dibujo de fachada que por su definición, muy superior al resto de los dibujos, consideramos que pertenece a otro proyecto, a la cual se le añade una anotación que dice: "Una fachada (dos veces $2.20 \mathrm{~m}=4.50 \mathrm{~m}$ )". Escaneando dicha fachada y escalándola en el programa de dibujo nos damos cuenta que 4.50 metros es la distancia hasta el arranque de la bóveda. Para que todo encaje el forjado debería ser una pieza muy fina de madera de 10 centímetros de espesor. Vemos como una escalera de 12 escalones de 30 centímetros de huella y 19 centímetros de contrahuella cabe de forma holgada en dos tramos dejando un paso previo y un descansillo de 1 metro.

No tenemos información relativa a las carpinterías exteriores, cómo hipótesis se ha dibujado un esquema muy básico en planta que nos permitiese acotar los espacios interiores.

En cuanto a los tabiques de división interior nos hemos limitado a dibujar lo sugerido por Le Corbusier. En $L a$ Euvre Complète, página 116, encontramos lo siguiente: “... Los divisiones dentro de estos espacios pueden variar entre compactas, transparentes y paneles translúcidos, según las necesidades.” Sin embargo no tenemos indicios gráficos de dichos paneles, ya que apenas hay dibujadas particiones separando usos.

Para entender el interior de la vivienda habría que analizar el programa de necesidades. En La Euvre Complète, página 121, encontramos una anotación que dice: "Planta baja: recepción. Planta primera: apartamentos. Planta segunda: habitación de invitados. Planta tercera: depósito de agua”. En el croquis 29993A@FLCADAGP se detalla una lista con el programa de necesidades que dice: "Taller no grande, despacho de mayordomía, sala común, habitación del señor y de la señora, 2 habitaciones de jóvenes, 1 habitación de 
amigos, 2 habitaciones de servicio doméstico”. Para entender cómo se distribuirían los usos tenemos que irnos a croquis posteriores. En el croquis 29993E@FLC-ADAGP donde se representa una primera versión de la planta baja, el taller se encuentra en el área sur de la casa, hay dos salones, uno en el área norte y otro al oeste pegado al gabinete de vistas y por último el servicio se encuentra en el área este de la casa. En el último croquis dibujado para la planta baja, el 29995A@FLC-ADAGP, el salón se mantiene en el área norte, ocupando parte de las crujías 5 y 6, el taller se sitúa al oeste, pegado al gabinete de vistas, el despacho de mayordomía en el área sur de la crujía 7, la cocina ocupa la crujía 8 y el área de servicio está situada en la crujía 10, separado por el paso descubierto que conforma la crujía 9. En este último dibujo apenas se sugiere unas particiones que separan el despacho de mayordomía, la cocina y el taller del resto de la zona social. En cuanto al mobiliario todo queda en un mueble en la cocina y unos muebles modulares en el taller.

Si nos vamos al croquis 29994B@FLC-ADAGP, que representa la planta primera, encontramos unas divisiones que dividen los tres dormitorios, el del padre, el del hijo y el de la hija, quedando una zona diáfana en el desembarco de la escalera. Se insinúan dos núcleos húmedos que podrían corresponder a los baños asociados al dormitorio de los padres y al del hijo. Como mobiliario tan solo aparece situada la cama matrimonial.

\subsection{Geometría de las bóvedas, sección transversal y detalle constructivo}

Para dibujar la geometría de las bóvedas en sección hemos partido de la imagen de fachada que aparece en $L a$ Euvre Complète, página 122, y que cómo hemos comentado anteriormente, consideramos que pertenece a otro proyecto. Es la única información que tenemos al respecto, por lo cual la usamos. Insertamos la imagen en el programa de dibujo y la escalamos, dándonos cuenta de que si la distancia entre ejes de muros es 4 metros, la distancia del suelo al arranque de la bóveda es exactamente 4,5 metros, concluyendo que si efectivamente la imagen pertenece a otro proyecto, las dimensiones mencionadas estaban bien arraigadas en la mente del maestro.

Utilizamos la geometría obtenida de la imagen de fachada respecto a una de las crujías en sección para dibujar la sección transversal completa de la casa, para ello insertamos en el programa de dibujo el croquis 29994D@FLCADAGP, que representa la sección, lo escalamos, superponemos la geometría obtenida anteriormente y dibujamos el resto de las crujías de la casa. Nos damos cuenta de que la sección, aparentemente un dibujo rápido a mano alzada está perfectamente proporcionada y al igual que las plantas encaja perfectamente con las medidas generales y la lógica geométrica de la casa.

Cómo ejercicio vamos a dibujar una hipótesis de detalle constructivo de cubierta. En La Euvre Complète, página 116, encontramos información sobre los materiales y sistemas constructivos a usar: "... El edificio debe ser construido por nativos y se debería usar la piedra local para pilares, muros o medios-muros". Y también "... Los pisos deben ser de madera y las bóvedas de ladrillo hueco, también hecha por nativos...” Apoyándonos en este texto sabemos que los muros están construidos de mampostería de piedra local y las bóvedas de ladrillo hueco. Aunque no se especifica en ningún lado entendemos que es necesario un dintel que transmita las cargas de las bóvedas a los muros, el cual pudiera ser de hormigón armado o, en escasez de este, de madera. También en La Euvre Complète, página 122, encontramos la siguiente anotación donde se habla de los materiales en el interior de la vivienda: "Resumen: juego de tres materiales: mampostería vista, bóvedas acabadas en cal, particiones de madera”. Con lo cual ya sabemos cuál es la terminación interior de las bóvedas y para la exterior probablemente deducimos que se pudiera tratar de una solería cerámica o la misma cal del interior. Entre el ladrillo hueco y la terminación exterior de la bóveda podríamos suponer que hubiera una capa de adobe.

En cuanto al desagüe de la cubierta resulta lógico pensar que fuera mediante canalones longitudinales en las intersecciones de las bóvedas y que terminasen en gárgolas, como sugiere el dibujo de fachada de Las Obras 
Completas anteriormente mencionado. Para rematar el testero de las bóvedas es necesario un elemento que pudiera ser un parapeto y que a su vez recogiese el canto de los dinteles. Siguiendo este razonamiento se ha dibujado una hipótesis de detalle constructivo, en el cual las dimensiones están tanteadas de forma aproximada.

\section{Los dibujos}

A continuación se presentan los dibujos que hemos realizado basándonos en los croquis del maestro.

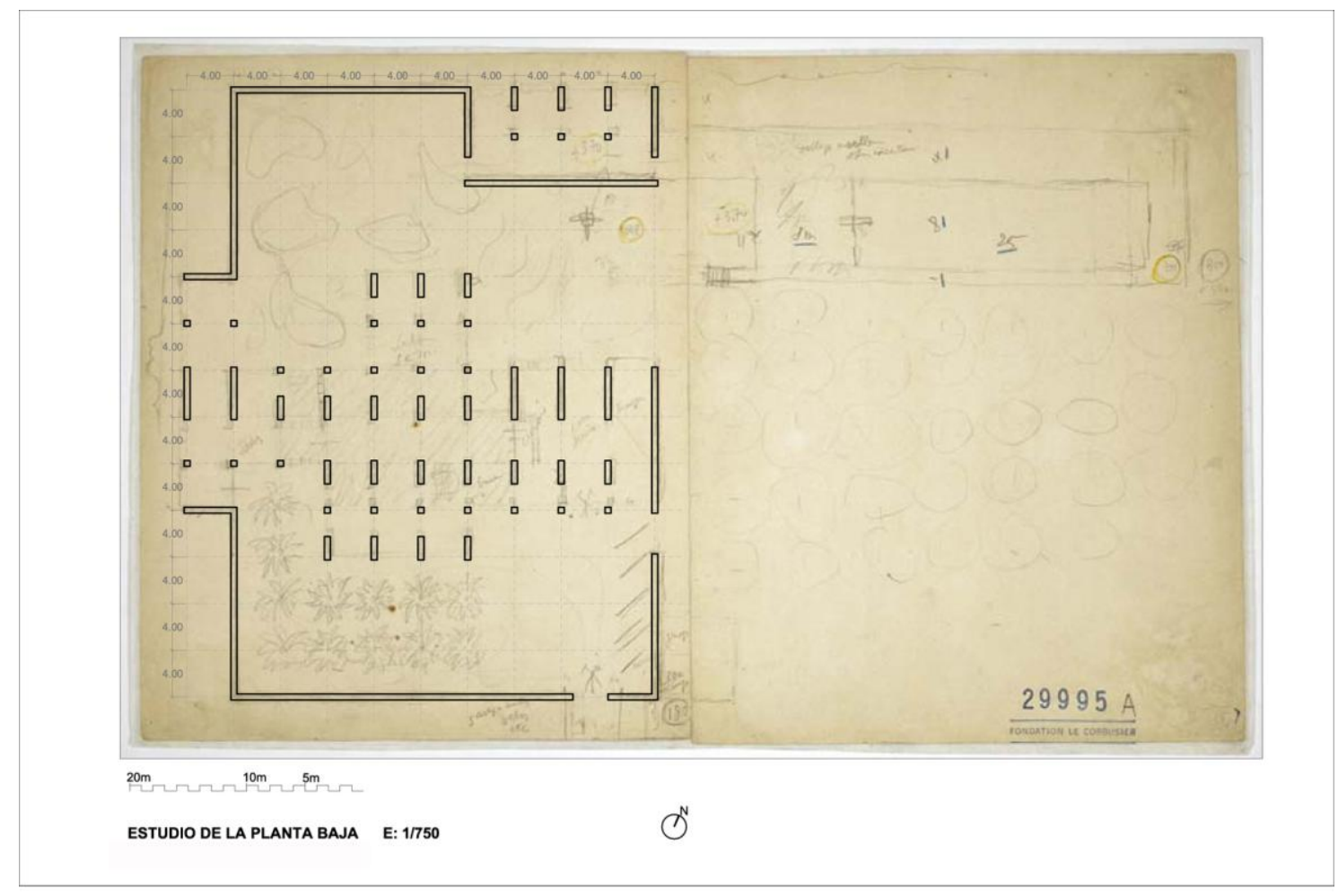

1.Estudio de la Planta Baja. Superposición sobre el croquis 29995A. 


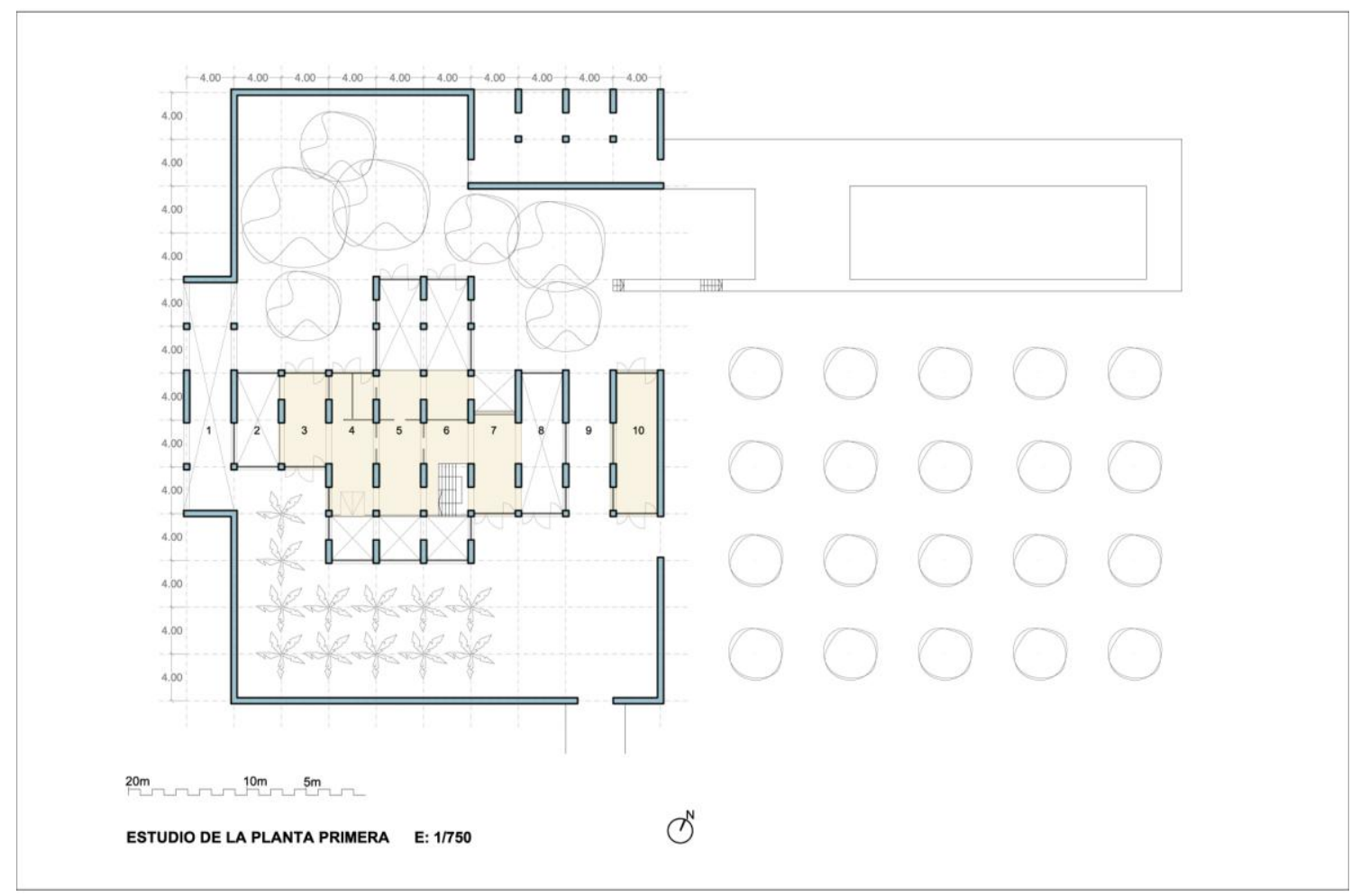

2. Estudio de la Planta Baja con todos sus elementos.

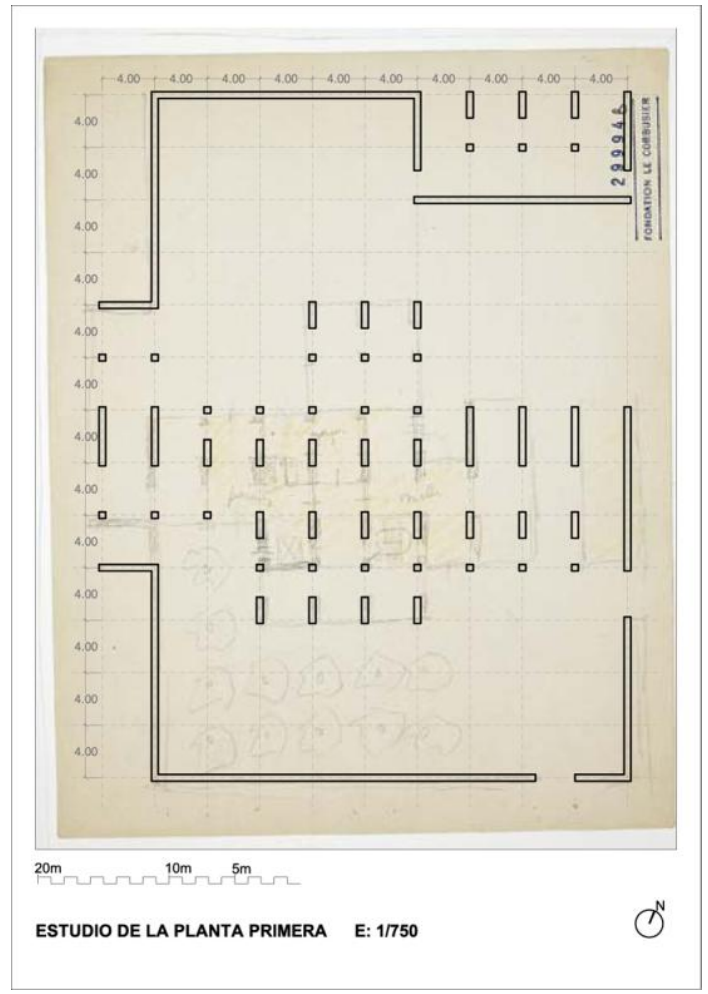

3.Estudio de la Planta Primera. Superposición sobre el croquis 29994B. 


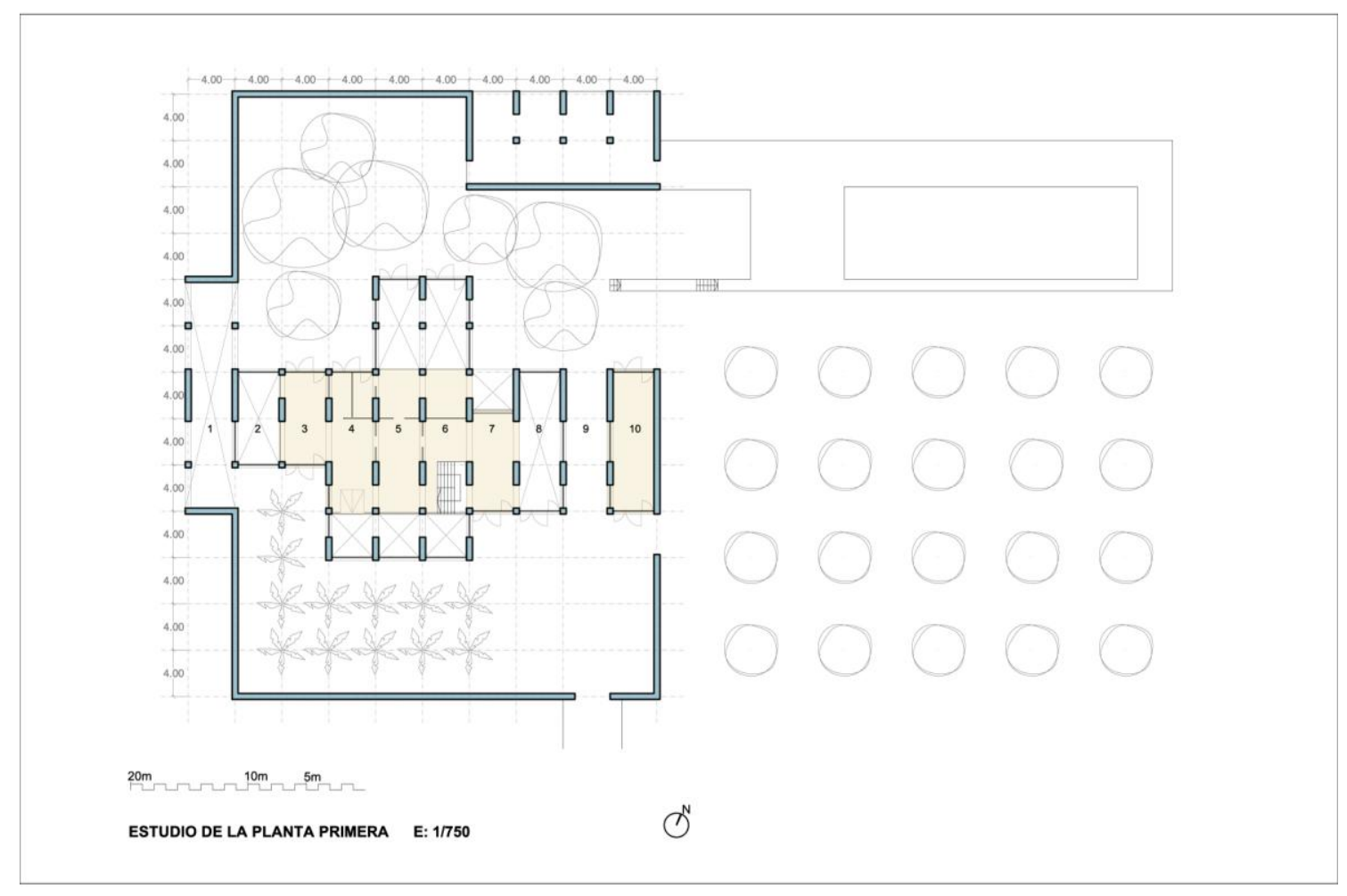

4. Estudio de la Planta Primera con todos sus elementos.

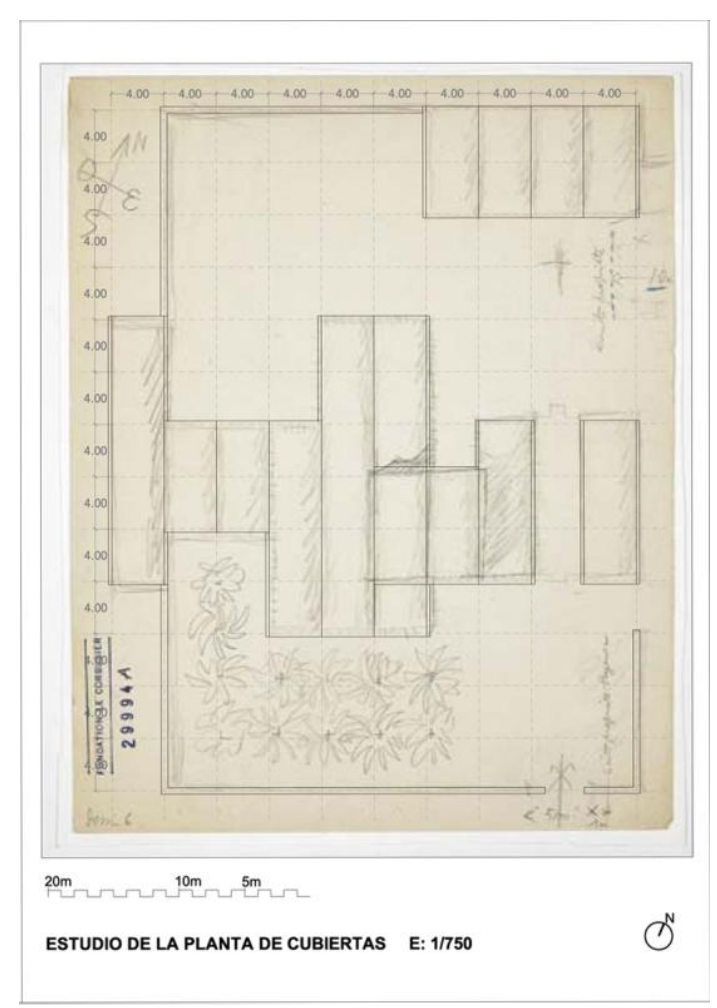

5. Estudio de la Planta de Cubiertas. Superposición sobre el croquis 29994A. 


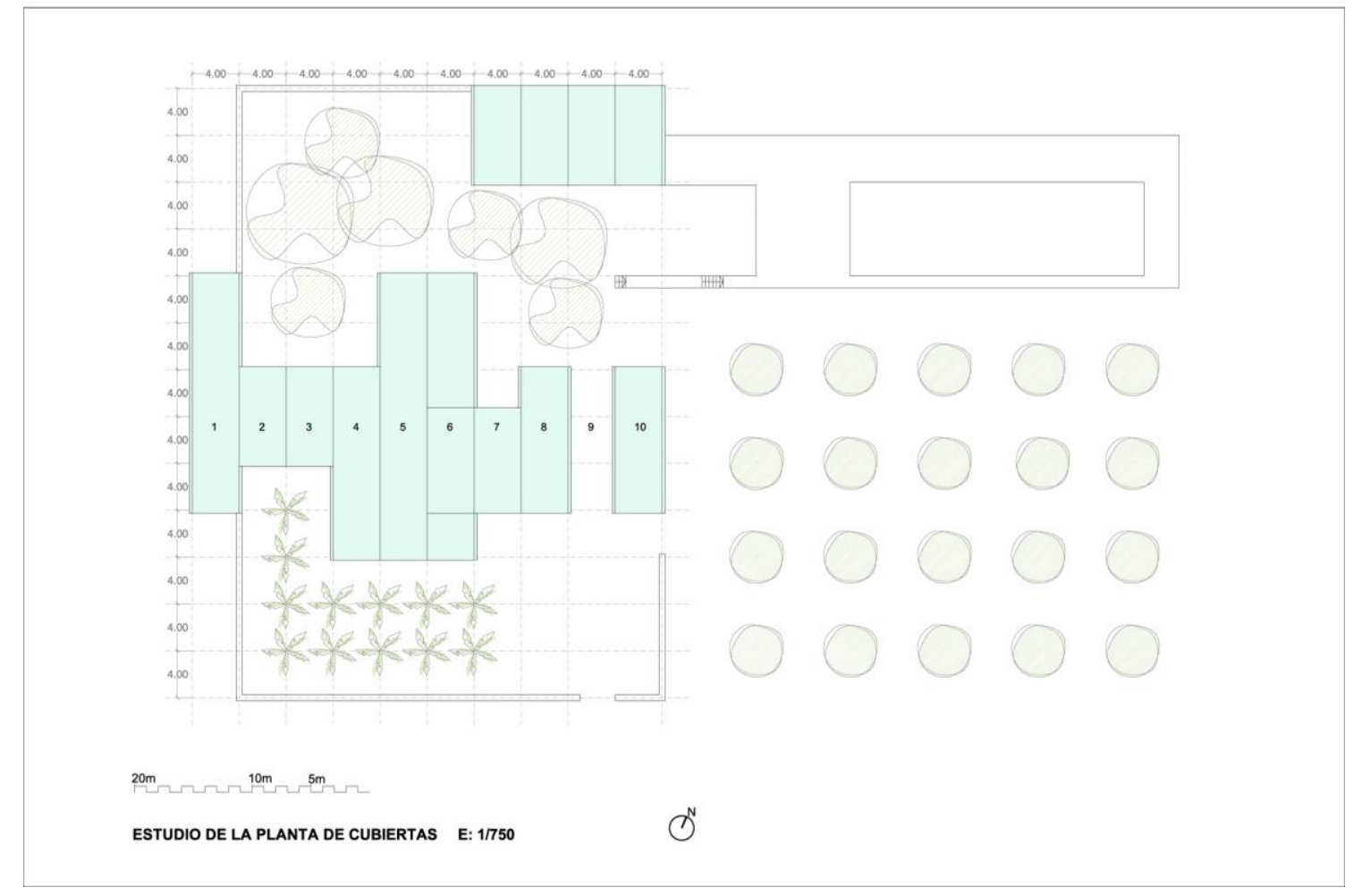

6. Estudio de la Planta de Cubiertas y la vegetación.

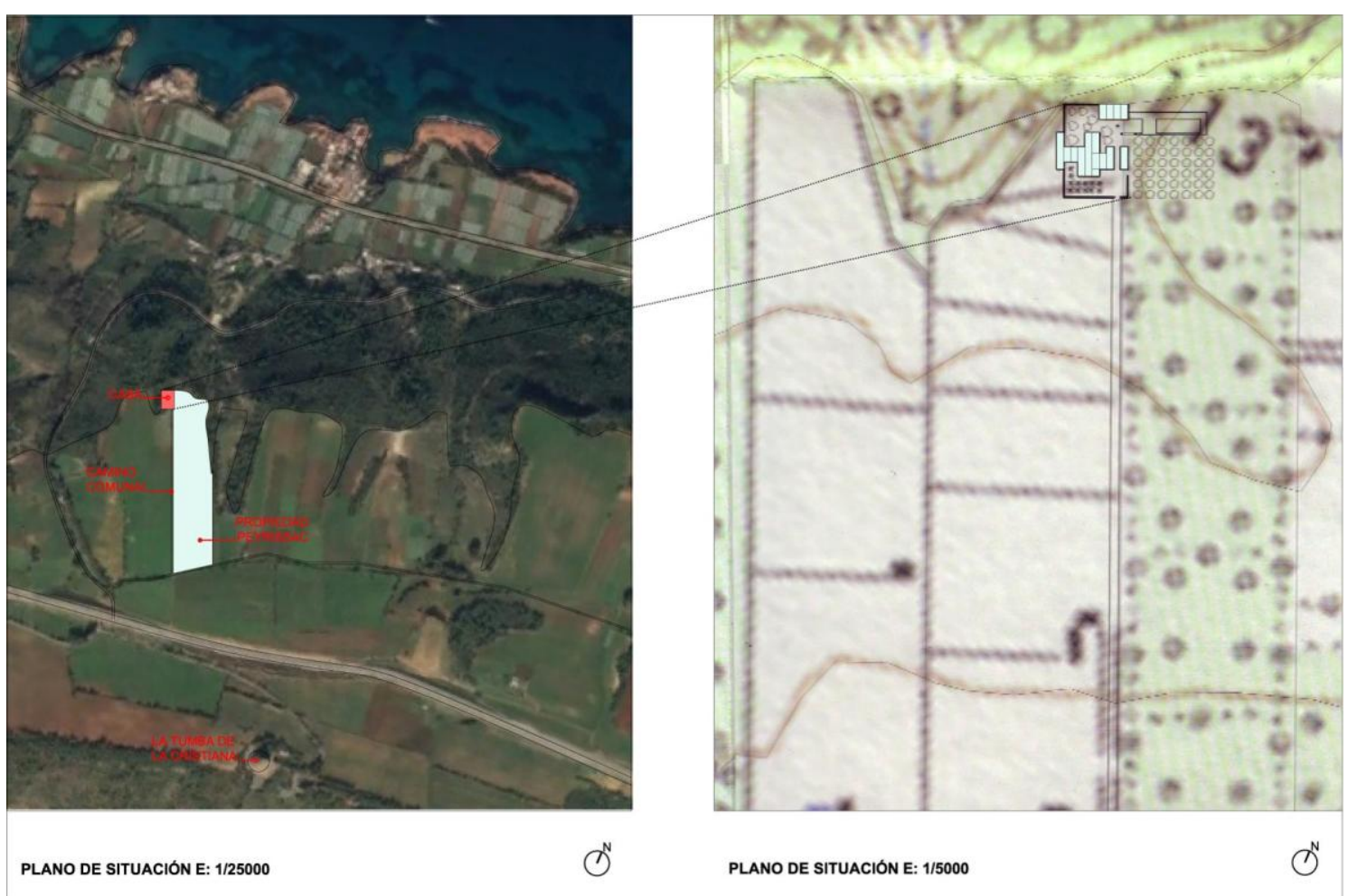

7. Situación de la parcela. 


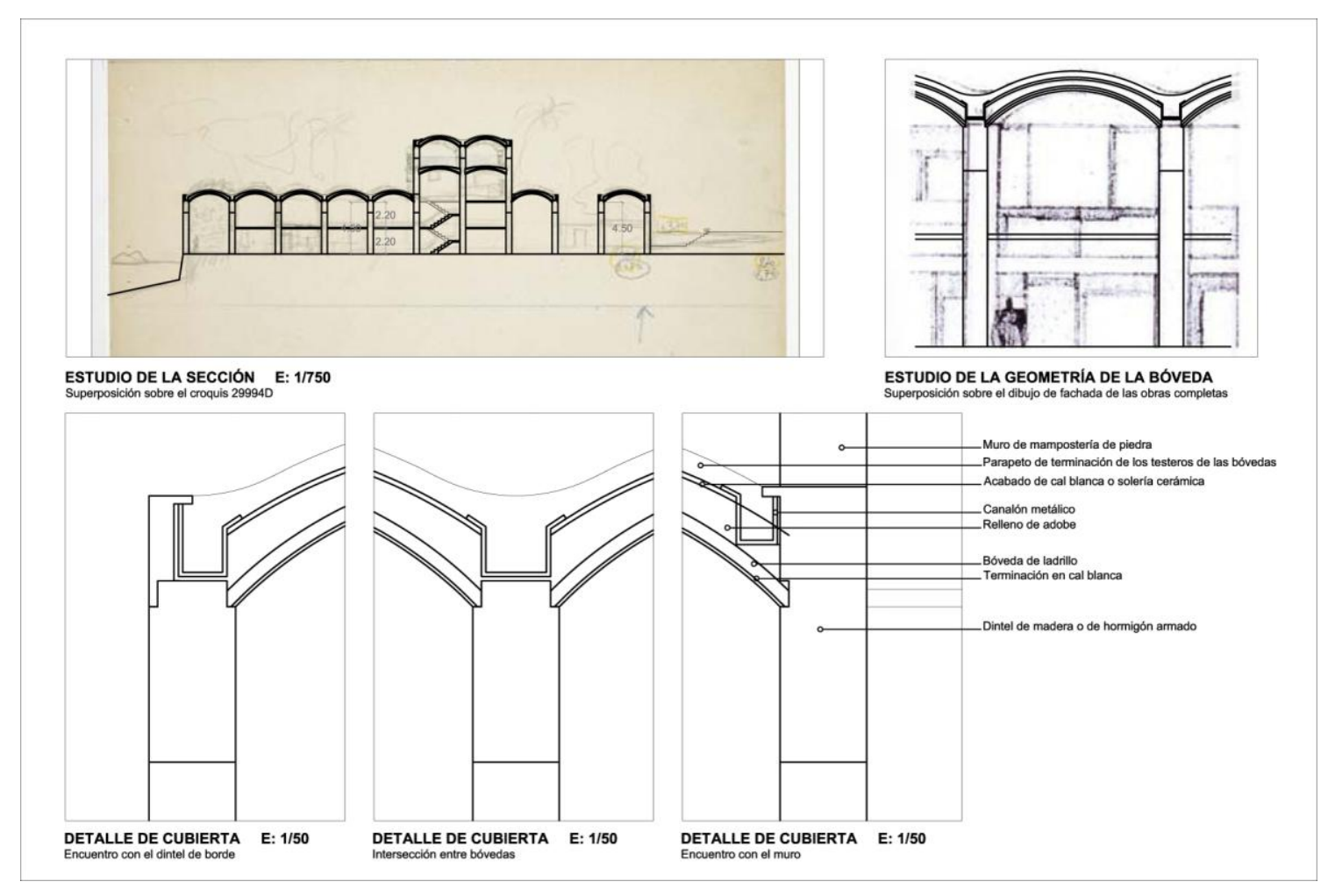

8. Sección y detalle constructivo.

\section{Conclusiones}

Para realizar los dibujos nos hemos limitado a seguir las indicaciones que los croquis originales del maestro nos daban, sorprendiéndonos el hecho de que todas las piezas encajaban como si se tratara de un puzle. Ayuda el hecho de que el diseño de la casa se basa en un sistema geométrico y constructivo extremadamente sencillo, con la cualidad de no por ello restarle riqueza espacial al conjunto.

Teniendo en cuenta que vamos por detrás del maestro, hemos parado de dibujar cuando se nos ha acabado la información. Quedan varios temas por resolver: cuestiones básicas de distribución y mobiliario, como una más lógica distribución de los núcleos húmedos, la ubicación de las particiones interiores y sus diferentes grados de opacidad, las carpinterías exteriores, tanto en planta como en alzado, y por último profundizar en el sistema constructivo.

De la misma forma que hemos supuesto cómo debería ser el detalle constructivo de cubierta y lo hemos dibujado, se podrían establecer hipótesis relativas a los temas referentes a distribución interior y carpinterías, utilizando ejemplos de otras obras de Le Corbusier o simplemente apropiándose del proyecto.

\section{Listado de imágenes}

Colección de 36 croquis originales dibujados por Le Corbusier en relación a La Casa Peyrissac y facilitadas por La Fundación Le Corbusier. Ver listado, clasificación y análisis de los mismos en las tablas 1, 2, 3, 4 y 5.

Imágenes $1,2,3,5,6, y$, realizadas como resultado del análisis de los croquis originales.

Imagen 7, realizada a partir de una imagen de Google Earth y de un parcelario de la zona. 


\section{Bibliografía}

Le Corbusier Ouvres Complètes Volume 4. 1938-46. 14ª ed. Birkahauser, Basel: W. Boesiger, 2013.

Tipasa. Algeria 1:50,000. Series P741, U.S. Army Map Service, 1941. Perry-Castañeda Library Map Collection. University of Texas. 